\section{ON SOME CASES OF OPERATION FOR CHRONIC NON-MALIGNANT DISEASE OF THE STOMACH.}

BY ARTHUR E. BARKER, F.R.O.S. ENG., PROFESSOR OF SURGERY AT UNIVERSITY COLLEGE AND SURGEON TO UNIVERSITY COLLEGE HOSPITAL.

A REVIEw of a series of more or less similar cases occurring within a given period is always interesting and profitable, and I propose to glance back at a group of nonmalignant cases of chronic gastric disease treated surgically which have been under my care comparatively recently-all since this time last year. Such a retrospect enables us in the first place to contrast allied affections of the same organ in their causation, symptoms, and effects. In the next place it gives us a good opportunity of examining into the forms of treatment which have been found most effectual. The present series is a fairly complete one of its kind. It includes only those cases of non-malignant chronic inflammatory disease of the stomach and duodenum on which $I$ have recently operated, and it includes them all ; the series is consecutive. The accompanying short table gives an epitome of the group and enables us in a moment to see the class of affections we have been dealing with and the leading features of each.

Consecutive Operations for Chronio Non-Malignant Disease of the Stomach and Duodenum.

\begin{tabular}{|c|c|c|c|}
\hline 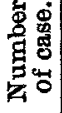 & $\begin{array}{l}\text { Sex, age, and } \\
\text { duration of } \\
\text { illness. }\end{array}$ & $\begin{array}{c}\text { Condition before and after } \\
\text { operation. }\end{array}$ & Result. \\
\hline 1 & $\begin{array}{l}\text { M., aged } 48 \\
\text { Jears. Illness } \\
\text { of six years' } \\
\text { duration. }\end{array}$ & $\begin{array}{l}\text { Duodenal ulcer with severe hæmor- } \\
\text { rhage from bowel. Also severe } \\
\text { pain after food. Emaciation. } \\
\text { Weight before operation, } 8 \text { st. } 9 \text { ! lb. } \\
\text { When last seen health was excel- } \\
\text { lent. Weight } 10 \text { st. }\end{array}$ & Recovered. \\
\hline 2 & $\begin{array}{l}\text { F., aged } 48 \\
\text { years. Ill for } \\
\text { six years. }\end{array}$ & $\begin{array}{l}\text { Gastric ulcer; " hour-glass" con- } \\
\text { traction; extreme emaciation. } \\
\text { Weight before operation, } 5 \text { st. 10 Ib. } \\
\text { When last seen health was excel- } \\
\text { lent. Weight over } 9 \text { st. }\end{array}$ & Recovered. \\
\hline 3 & $\begin{array}{l}\text { F., aged } 56 \\
\text { years. Ill for } \\
\text { one and a half } \\
\text { years. }\end{array}$ & $\begin{array}{l}\text { Pyloric stenosis due to ulcer. } \\
\text { Emaciation; pain. Weight before } \\
\text { operation, } 8 \text { st. } 121 \mathrm{~b} \text {.; some time } \\
\text { before was } 10 \text { st. } 2 \mathrm{lb} \text {. When last } \\
\text { seen health was excellent ; weight } \\
\text { had increased. }\end{array}$ & Recovered. \\
\hline & $\begin{array}{l}\text { M., aged } 45 \\
\text { years. Ill for } \\
\text { three years. }\end{array}$ & $\begin{array}{l}\text { Pyloric stenosis due to chronic } \\
\text { ulcer. Pain, vomiting, and } \\
\text { emaciation. Weight before opera- } \\
\text { tion, } 9 \text { st. } 9 \text { lb. } 12 \mathrm{oz} \text {.; nine months } \\
\text { later weight was } 10 \text { st. } 16 \frac{1}{2} \text { lb. }\end{array}$ & Recovered. \\
\hline 5 & $\begin{array}{l}\text { F., aged } 24 \\
\text { years. IIl for } \\
\text { three years. }\end{array}$ & $\begin{array}{l}\text { Bleeding gastric ulcer. No stenosis } \\
\text { of the pylorus. Repeated bæmor- } \\
\text { rhages, pain, and vomiting. Not } \\
\text { any emaciation, but much ten- } \\
\text { derness over fundus of the } \\
\text { stomach Weight before opera- } \\
\text { tion, } 8 \text { st. } 9 \mathrm{lb} \text {. }\end{array}$ & Recovered. \\
\hline 6 & $\begin{array}{l}\text { M., aged } 33 \\
\text { years. Ill for } \\
\text { four years. }\end{array}$ & $\begin{array}{l}\text { Pyloric stenosis from ulcer. Pain, } \\
\text { vomiting, tenderness, and emacia- } \\
\text { tion. Weight before operation, } \\
9 \text { st. } 2 \text { lb. }\end{array}$ & Recovered. \\
\hline 7 & $\begin{array}{c}\text { M., aged } 47 \\
\text { years. Ill for } \\
15 \text { years. }\end{array}$ & $\begin{array}{l}\text { Pyloric stenosis due to gastric ulcer. } \\
\text { Pain, vomiting, great dilatation, } \\
\text { gastric tetany and rigors, and } \\
\text { emaciation. Weight before opera- } \\
\text { tion, } 7 \text { st. } 12 \text { b. }\end{array}$ & Recovered. \\
\hline 8 & F. Ill for & $\begin{array}{l}\text { Pyloric stenosis from ulcer; scar } \\
\text { hard. Moderate emaciation, pain, } \\
\text { vomiting, bleeding by bowel, and } \\
\text { tenderness over fundus of the } \\
\text { stomach. }\end{array}$ & Recovered. \\
\hline 9 & $\begin{array}{c}\text { F., aged } 35 \\
\text { years. Ill } \\
\text { several years. }\end{array}$ & $\begin{array}{l}\text { Pyloric stenosis with lump about } \\
\text { the pylorus of doubtful nature. } \\
\text { Extreme emaciation. Weight } \\
\text { before operation, } 4 \text { st. } 3 \text { lb. }\end{array}$ & Recovered. \\
\hline 10 & $\begin{array}{l}\text { F., aged } 52 \\
\text { years. Illness } \\
\text { of } 10 \text { years' } \\
\text { duration. }\end{array}$ & $\begin{array}{l}\text { Pyloric stenosis due to small } \\
\text { ulcer. Qreat exhaustion and } \\
\text { emaciation. Great pain and daily } \\
\text { vomiting. }\end{array}$ & Recovered. \\
\hline
\end{tabular}

Let us look a little more closely into these point first place, all, with two exceptions, required treatment on account of obstruction to the escape of food from the stomach into the intestine. The two others claimed interference on account of chronic ulcers, in the one case of the stomach and in the other of the duodenum, which ulcers were bleeding to a disquieting and perhaps dangerous degree for long periods lasting over years in spite of good treatment. But apart from this symptom there was the danger that at any time either of the ulcers might perforate into the abdominal cavity and lead to disastrous effects.

In the cases of stenosis one showed the effects of a chronic ulcer upon the body of the stomach, contracting it into an "hour-glass" cavity which could not properly be emptied into the duodenum; the others were all instances of con. traction of the pylorus itself in which either the contraction would be seen in the shape of a puckered scar through the peritoneal covering or felt by the finger pushed into its ring by invaginating the wall of the stomach (Hahn).

With the epitome before us it is hardly necessary to describe any case in detail. It will be more profitable to review the causation, symptoms, and effects practically common to all. All the cases of stenosis began with the usual symptoms of dyspepsia-i.e., discomfort or pain after food, followed sooner or later by vomiting of undigested matter and usually by more or less bleeding. Then, under restricted dieting and other more direct medical treatment remissions took place and often considerable improvement, so that but little discomfort was felt. But then, in all these cases at least, a return of the trouble occurred on resumption of the ordinary dietary. This was again met by the usual treatment of dyspepsia with the addition in the later cases of washing out of the stomach some hours after food. This last means of relieving the stomach of its residuum of fermenting food has proved a most valuable addition to the treatment of those cases in which either a chronic ulcer was present or the result of such an ulcer in the form of a contraction of a part of the stomach or pylorus. And it appears probable, from what we have seen in these and many other cases, that were washing out more frequently employed in the various forms of chronic dyspepsia as a regular treatment we should see less of the evil effects of acute and chronic gastric ulcer. But in the later stages of gastric disease where an ulcer is becoming chronic and is producing stenosis it can only, of course, be regarded as a valuable palliative and again as a useful preparation for operative treatment. The cases in this list, although several of them were thus treated by lavage for long periods, were so chronic that a permanent cure was not effected in any.

Another symptom was present in most of the casesnamely, dilatation, more marked, of course, in those who came to us after little or no preliminary treatment than in those who had been kept on restricted and suitable diet. It is quite plain that dilatation of the stomach can be more or less prevented by careful diet, so long as there is even a small outlet for the food from the stomach. It is only where the latter is almost absent that the dilatation is extreme. But it must not be forgotten that besides actual organic contraction of the stomach or pylorus the outlet may be contracted by the sphincter action of the pylorus induced by irritation of improper or fermented food with or without an excoriation or ulcer of the ring. In these cases the regular removal of an undigested residuum from the stomach some hours after meals eliminates the source of irritation and gives the pylorus rest. This is productive of the most marked immediate benefit and may even, if regularly carried out, result in a return to nearly normal conditions in the pylorus by removing the irritant regularly and giving the ulcer or abrasion complete rest for hours at a time, during which the sphincter is relaxed, for it must never be forgotten that one of the functions of the pylorus is to prevent improper food or ill-digested material from gaining its way into the small intestine. For this reason all semi-putrid material in a dilated stomach is prevented by spasm of the sphincter pylori from entering the duodenum.

The dilatation of the stomach in these cases has been estimated in the first place by percussion. This, however, is clearly an unsatisfactory method of testing the size of the organ if taken alone. If the stomach contains much gas its size is easily demonstrated by percussion. But in many of these cases there was but little gas to a large quantity of fluid and undigested food. I therefore make it a rule in all these cases to test the point of dilatation first by percussion, then 
by observing how much is drawn off from the organ by syphon, next by filling the stomach again with water until discomfort is produced and measuring the quantity which can now be withdrawn, and finally by inflating the now empty organ with a Higginson's syringe and percussing it out again. This can all be done quickly and without much distress while at the same time the washing out is beneficial. In the penultimate case operated on the dilatation when gentle injection of air was used was seen to be extreme and the border of the organ could be distinctly made out through the very thin abdominal walls as a ridge sweeping in a long curve some inches helow the umbilicus. This method of injection of fluid or air has a further aim. It enables us mainly to estiruate the muscular power of the stomach-in other words, whether there is hypertrophy of its muscular walls or an atonic condition combined with dilatation. This point is of importance. If the fluid is returned with force it indicates, in the first place, that obstruction is probably marked, but that after a gastro-enterostomy a rapid return to the normal may be expected. But if the fluid in a largely dilated stomach is returned with very little force or has to be syphoned off there may be stagnation in the organ from atony even after such an operation, and it may be better to postpone the latter until, by a course of washings and tonics, the organ is more or less restored to its normal contractility. For nothing can be worse for the chances of good union between the stomach and intestine than the stagnation of blood, mucus, bile, and swallowed food around the new opening.

In the two cases in which gastro-enterostomy was done on account of hæmorrhage there was no dilatation when seen by us. The patients had been suffering from vomiting of blood on and off with pain in the one case for three years and in the other for six years, with passage of large quantities of blood by the bowel. Both had pain after food. These symptoms were only partly relieved by treatment in this hospital and elsewhere and always recurred on remission of medical treatment and return to anything like normal diet. The fear in these cases was either that the bleeding would prove fatal or that perforation would sooner or later take place unless the stomach was regularly relieved (one was an ulcer in the duodenum). Almost all these cases then had had careful medical treatment before the question of surgical interference was entertained.

The preparation for the latter was the routine one with me. It consisted in the cleansing of the stomach for several days by washing and the administration of only small quantities of sterile fluid food. The mouth was at the same time cleansed and carious teeth were extracted. This I hold to be of the utmost importance. Concurrently the patients were given 10 grains of carbonate of bismuth three times daily as an intestinal antiseptic and the lower bowels were washed out with enemata. Where great emaciation was present the normal amount of water was given to the tissues by hypodermic instillatinn of normal saline solution, a pint morning and evening, and to this $I$ have added 5 per cent. of glucose with much benefit. Nutrient enemata were also the rule for days before. When by these means the stomach had been cleansed and the forces of the patient recuperated, after thorough antiseptic cleansing of the skin the operation was carried out as rapidly as possible with the exclusion of strong germicide from all contact with the abdominal contents. The operation in all these cases was done without Murphy's button or any appliance of the kind. In every case it was the retrocolic variety (v. Hacker). The suturing was done in the same way as in my first case 15 years ago-namely, by uniting the serous and muscular coats behind the proposed opening, before the latter was made, and then by opening the gut and stomach and uniting the resulting edges and finishing the continuous suture over the front which had been begun before the viscera had been opened. When I published this method 15 years ago I did not know that it would become the classical one, as has been the case. The abdominal wound was closed in every case except one by sutures, including all the layers with the skin. Oddly enough, in the exception in which buried sutures were used in addition to skin stitches the whole wound yielded on the tenth day after the latter had been removed from a flawless primary intention wound. The same evening the wound quietly gaped during a trifling movement of the patient in bed. Four days later I found the wound widely open on removing the dressings and the omentum and small intestines exposed. The patient, however, was in excellent condition and with a normal temperature. The edges of the wound were covered with lymph and a little fresh blood-clot; there was no trace of pus. I simply scraped off the lymph, wiped the edges dry, and sutured through the whole thickness of the abdominal wall, removing the old buried sutures at the same time. The wound healed as thoroughly as if by first intention and the scar was quite sound when the patient left the hospital.

In the course of operations such as those applied to these cases there are countless small details upon which their success greatly depends but which I should find it very difficult to describe adequately and at the same time briefly. They can only be learned by close attention to every step of the procedure. Fortunately, these cases have followed each other so steadily and closely that those who attend our hospital have had every opportunity of becoming familiar with them and I need attempt no detailed description of them.

There remain, then, to be considered only some points in regard to the after-treatment of these cases of non-malignant pyloric stenosis in which posterior gastric enterostomy has been done. In the first place, while on the operating table if there were any signs of shock the patient received in the areolar tissue of the arm near the axilla a pint of the saccharo-saline solution. This and the maintenance of the body heat by hot-water bags and wrapping in cotton-wool was found quite adequate in all to prevent the evil effects of shock which was hardly seen in any, even the most asthenic. On being removed to bed the patients were placed on their backs, at first a little inclined to the right. As soon as they wished (generally the second day) they were kept in the semi-recumbent position while awake and were laid on their right side for sleep or change of position. All this seems to have several advantages. In the first place, whatever fluid is in the stomach, be it bile, blood, or food, and mucus, appears more readily to find its way into the new outlet of the stomach than when the position is directly flat on the back. Then there is less chance of oedema of the lungs when the thorax is semi-erect. Again, the occasional change of position with these patients suffering in most cases from the most extreme emaciation, is the surest way of warding off bedsores and securing comfortable sleep. But doubtless the most important factor of all is the increase in the capacity of the chest as the abdominal viscera sink downwards in the almost vertical position of the trunk. Lung troubles are, as we know, the bane of abdominal opera. tions and without going into all the theories as to their causation it must be admitted that restriction of the free movements of the thorax contribute at all events to their danger.

The next point worth noting is that all these patients have been fed from the first by the mouth as well as by the rectum. As soon as it has been clear that chloroform nausea was not present or passing off they have had albumin water with a drachm of brandy at first half an ounce every two hours, then every hour, and then double the amount until about the fifth day they were ready for Benger's food, pounded fish, or chicken.

A further matter attended to has been the tendency in many cases to regurgitation of bile into the stomach during the first few days when it may produce a sense of weight and discomfort or induce vomiting. This was shown by Carle and Fantino to be almost the rule in such cases, even when patients were almost unconscious of it. In almost every one of these cases, then, I have introduced a rubber tube into the stomach during the first 24 bours with a view to relieving the organ of bile with blood and mucus, which is usually there and may be decomposed if left there. And I have been astonished in several cases at the amount of fluid lying stagnant in the organ after operation and also at the amount of relief given. So great is the latter that patients who have once had the tube will assent to it again if they do not actually suggest it. There has been very little need in these cases, as a rule, of washing out the stomach at the same time that the fluids hare been syphoned off. But in some cases, especially where there was oozing of blood from the stomach and intestinal wounds, washing out with boric solution or mere normal saline solution has appeared to be beneficial. All the wounds have healed blamelessly. But in one, as already mentioned, in a man suffering from the most extreme emaciation, the scar opened on the tenth day and had to be re-sutured. Not the slightest ill result followed. 
As to the results, all have recovered and the change in health in those who have had time to show it has been most remarkable. The patients have all increased in weight and lost all their other symptoms. It is quite clear to me now that in such cases of non-malignant stomach disease lasting for years in spite of skilled medical treatment the formation of a short cut between the fundus of the stomach and the upper part of the jejunum offers a very good prospect of complete relief and with a very moderate risk. And as the principles underlying these operations are better understood and our technique improves in detail these risks cannot but become less and less to judge by the history of other operations.

\section{CASES OF GASTRO-ENTEROSTOMY FOR NON-MALIGNANT AFFECTIONS OF' 'THE STOMACH.'}

BY T. KENNEDY DALZIEL, M.B., C.M. EDIN., F.F.P.S. GLASG.,

PROFESSOR OF SURGERY, ANDERSON'S COLLEGE, AND SURGEON TO THE WESTERN INFIRMARY AND ROYAT HOSPITAL FOR SICK CHILDREN, GLASGOW.

THE operation of gastro-enterostomy has so long since passed the region of experiment that at this date it is hardly necessary to enter into the question of its propriety in suitable cases. Of course, the object of the operation is to enable the stomach to empty its contents into the intestine in cases where, from organic or functional causes, that does not occur with sufficient readiness to prevent fermentation, in consequence of which a state of irritation is induced in the mucous membrane of the stomach as well as a general deterioration of health from starvation and the absorption of toxins. Of the utility of the operation in pyloric obstruction, simple or malignant, there can, of course, be no doubt whatever, and it seems to me that much benefit may be obtained in cases where the normal action of the stomach is prevented, or at least materially retarded, by adhesions, either in the region of the pylorus or over the general surface of the organ, due in many cases to plastic peritonitis from a perforating gastric ulcer or to pathological changes in the neighbouring viscera. It is probable that in another group of cases due merely to functional disorder, where we have dilatation of the organ without obstruction at its outlet, but accompanied by the usual fermentative changes, we have in gastro-enterostomy a means of draining the organ and thereby of alleviating the misery which has been found by the physician to be unrelieved by any ordinary method of treatment. No doubt the operation would be most useful and most frequently practised in those cases where there are marked organic causes leading to dilatation. The establishment of the operation as a useful and trustworthy means of treatment will necessarily depend upon the mortality which accompanies it.

I beg leave to bring before this section a group of 30 operations undertaken for the cure of apparently incurable dyspepsia, many of them with evidence of marked pyloric obstruction. The patients had been under treatment prior to operation for periods varying from two to 17 years, 16 of them with definite history of ulceration. At the operation it was found that 18 of these cases presented well-marked contraction of the pyloric orifice, and in two cases this was so extreme as practically to amount to occlusion, so that it had been found necessary to wasn out the stomach two, and occasionally three, times a day to render life tolerable, and from the history it was evident that little or no material entered the intestinal canal. The degree of contraction was estimated by examination from within the stomach. In eight cases the obstruction was due to adhesions the result of peritonitis originating from old tuberculous glands behind the pylorus, these adhesions so compressing and kinking it as to interfere with the emptying of the stomach. In three cases the posterior wall of the stomach was found adherent to such an extent as to interfere with its muscular action and in one of these the adhesions were so extensive and their contraction was so considerable that the

I A paper read before the Surgery Section of the British Medical Aswociation at Manchester on August Ist, 1902 . pylorus was pulled backwar-'s and to the left side so that it simulated a tumour of the splenic flexure of the colon, for which, indeed, it was mistaken prior to operation. In one case there was marked dilatation of the stomach without any apparent physical cause. Many of these patients were in a state of great emaciation from prolonged malnutrition. In three of the cases of external adhesions I had previously operated with only temporary relief after their separation-an experience which seems to be not unusual ; indeed, I find that of seven cases in which I have divided adhesions only one remains permanently benefited, so that I am inclined to think that in such cases it is better to put the stomach at rest by the performance of a gastroenterostomy.

The symptoms presented by the individual cases were, as usual, varied and variable, as was also the amount of dilatation. In all, the misery and suffering were sufficiently great to render the patients very willing to run the risk of the operation with prospects of relief. In those cases where the trouble was located not in the pylorus itself, the dilatation was naturally least, and in four of these cases did not indeed exist to any extent, although all the symptoms of an obstructive dyspepsia were present. No doubt the amount of dilatation in many of these cases had been kept in check by regular lavage of the stomach practised in periods varying from two months to three years. In almost all the cases, pain was a prominent symptom; and, indeed, in four cases, while there had been no vomiting except on very infrequent occasions, the pain was so persistent and intense, and so utterly unrelieved by medicinal treatment, that an exploratory incision was advised and a physical condition was found which warranted the gastro-enterostomy being performed.

As a preliminary to operation careful lavage of the stomach was carried out in all cases for two days before the operation, plain water being used and great care being taken thoroughly to empty the stomach immediately before operation. With all the ordinary antiseptic precautions an incision was made above the umbilicus, in the earlier cases through the middle line but later through the middle of the left rectus muscle. With the exception of four cases all the operations have been that of posterior gastro-enterostomy, the anterior being performed in one case by selection and in the others being rendered necessary by the presence of extensive posterior adhesions which rendered it impossible to gain access to that surface of the stomach.

The usual method of operation has been to withdraw and turn up the omentum and colon, guarding these with large, flat, natural sponges wrung out of sterilised saline solution. The posterior wall of the lesser peritoneal bag is opened with a cut from the scissors and this wound is stretched sufficiently to allow a portion of the stomach, preferably near the junction of the pyloric with the middle third, to be drawn through, so that the opening may be situated high up-that is, towards the lesser curvature. A loop of the jejunum, readily found by looking for the termination of the duodenum, is then withdrawn and approximated to the selected portion of the stomach and fixed to it by means of hook forceps about two and a half inches apart, so that ample room may be left for the stitching. In all cases three rows of continuous sutures were inserted : the first, that to be furthest from the opening, being of silk; the second, of catgut which may absorb in from four to six days; and the third, next to the lumen of the canal, of fine intestinal silk-the idea of the intervening catgut being to secure a zone of adhesions without the prolonged presence of a foreign body, so that the outer retaining suture may be less easily contaminated by sepsis from the necessarily exposed wound of the mucous membrane. After the first two rows of sutures have been inserted half-way round that point where the opening is to be made, they are carefully guarded with sterilised gauze and the jejunum is opened in its long axis, opposite to the attachment of the mesentery, and a corresponding opening is made in the long axis of the stomach. These openings have generally been about two inches in length. All bleeding points are carefully ligatured, and while this is being done plugs of gauze are inserted into both openings to prevent escape of contents, which for the most part consist of mucus and bile. But rarely has this given rise to any trouble, since the parts can be held up sufficiently to prevent overflow. Finally, the third row of sutures, including all the coats, is inserted quite close to the gut wound, and thereafter the second and first rows are carried round to where they started. 'The opening 